\title{
Flexible stabilization of the distal tibiofibular syndesmosis: clinical and biomechanical considerations: a review of the literature
}

\author{
Annick den Daas · Wouter J. van Zuuren • \\ Stéphane Pelet $\cdot$ Arthur van Noort • \\ Michel P. J. van den Bekerom
}

Received: 23 May 2012/ Accepted: 8 October 2012/Published online: 25 October 2012

(C) The Author(s) 2012. This article is published with open access at Springerlink.com

\begin{abstract}
Syndesmotic rupture is present in $10 \%$ of ankle fractures and must be recognized and treated to prevent late complications. The method of fixation is classically rigid fixation with one or two screws. Knowledge of the biomechanics of the syndesmosis has led to the development of new dynamic implants to restore physiologic motion during walking. One of these implants is the suture-button system. The purpose of this paper is to review the orthopaedic trauma literature, both biomechanical and clinical, to present the current state of knowledge on the suture-button fixation and to put emphasis on the advantages and disadvantages of this technique. Two investigators searched the databases of Pubmed/Medline, Cochrane Clinical Trial Register and Embase independently. The search interval was from January 1980 to March 2011. The search keys comprised terms to identify articles on biomechanical and clinical issues of flexible fixation of syndesmotic ruptures. Ninetynine publications met the search criteria. After filtering using the exclusion criteria, 11 articles (five biomechanical and six clinical) were available for review. The biomechanical studies involved 90 cadaveric ankles. The suture-
\end{abstract}

\footnotetext{
A. den Daas $(\bowtie)$. W. J. van Zuuren · A. van Noort .

M. P. J. van den Bekerom

Department of Orthopaedic Surgery, Spaarne Hospital,

Spaarnepoort 1, PO Box 770, 2130 AT Hoofddorp,

The Netherlands

e-mail: a.dendaas@gmail.com

M. P. J. van den Bekerom

e-mail: bekerom@gmail.com

S. Pelet

Department of Orthopaedic Surgery,

Clinique Université Laval CHA-Pavillon Enfant-Jésus,

1401, 18 ème Rue, QC G1J 1Z4, Canada
}

button demonstrated good resistance to axial and rotational loads (equivalent to screws) and resistance to failure. Physiologic motion of the syndesmosis was restored in all directions. The clinical studies (149 ankles) demonstrated good functional results using the AOFAS score, indicating faster rehabilitation with flexible fixation than with screws. There were few complications. Preliminary results from the current literature support the use of suture-button fixation for syndesmotic ruptures. This method seems secure and safe. As there is no strong evidence for its use, prospective randomized controlled trials to compare the suture-button to the screw fixation for ankle syndesmotic ruptures are required.

Keywords Syndesmosis - Screw - Ankle fracture . Flexible implant $\cdot$ Instability $\cdot$ Biomechanical

\section{Introduction}

Syndesmotic instability occurs in approximately $10 \%$ of all ankle fractures and in $25 \%$ of all ankle fractures that require surgery $[20,25]$. The syndesmosis comprises the anterior and posterior inferior tibiofibular ligaments and a central interosseous ligament that extends more proximally as the interosseous membrane [2, 24]. Classic injuries associated with syndesmotic instability can be described as a pronationexternal rotation (PER) type injury (according to LaugeHansen) or a Danis-Weber type C classification [14, 23]. Weber B fractures with medial injury, occurring after supination-external rotation injury (SER IV), can also be associated with syndesmotic instability. Pure ligamentous injuries to the syndesmosis also occur, typically with external rotation injuries in athletics. All these injuries fall under the same indication requiring syndesmotic fixation [21]. 
Poor functional outcomes and the development of osteoarthritis due to widening and chronic instability of the distal tibiofibular syndesmosis have led to the widespread practice of anatomical restoration and stabilization of the ankle mortise and syndesmosis [9, 11, 29, 41]. For the treatment of syndesmotic instability, the AO/ASIF-group recommends a tibiofibular transfixation screw [12]. Problems with this type of fixation have been reported and included the following: late syndesmotic widening after screw removal; screw loosening; screw breakage; the need for a second operation to remove the screw; and morbidity associated with prolonged immobilization [5, 9]. To avoid this need for removal, bioabsorbable syndesmotic screws have been proposed [40]. However, these may fail before healing is complete or may cause osteolysis [4] and, in case of infection, may be difficult or even impossible to remove.

The more recent development is the suture-button (flexible implant) with the potential advantage of preserving physiologic motion in the tibiofibular joint [18]. Rigid fixation with a screw eliminates this normal motion, potentially resulting in pain or hardware failure [32]. An ideal implant to stabilize the tibiofibular syndesmosis should allow early mobilization and be strong enough to maintain reduction in the syndesmosis [19]. These characteristics appear to be met in the suture-button but little is known about the short- and long-term results of this implant [40]. The objective of this review is to highlight the pros and cons of suture-button fixation for stabilizing the distal tibiofibular syndesmosis based on the current available literature (biomechanical and clinical). Answers to the following questions are sought: Is the suture-button secure? Is it easy to apply? Is it efficient? Is it costeffective?

\section{Materials and methods}

A literature search was conducted to identify studies in which patients were treated for syndesmotic instability with a suture-button. Inclusion criteria were age (over 18 years), acute syndesmotic instability (isolated and with associated fracture) and treatment with the suture-button technique. The suture-button fixation technique was defined as any stabilization technique for syndesmotic instability which is not static and allowed for some degree of tibiofibular movement. Examples of fixation hardware meeting this criterion include the TightRope (Arthrex, Naples, FL, US), ZipTight (Biomet Warsaw, Indiana, USA), and Endobutton (Smith \& Nephew, Andover, MA, US). The exclusion criteria were as follows: animal studies, syndesmotic stabilization with other stabilization (static or fixed) methods and reports on fewer than two patients. Biomechanical and clinical studies were included
(Tables 1, 2). Article language was restricted to English, German and Dutch. For this search, the following Boolean operators were used: 'syndesmo*' OR 'tibiofibular' AND 'flexible fixation' OR 'suture' OR 'Acufex' OR 'Tightrope' OR 'Arthrex' OR 'Ziptight' OR 'EndoButton'. Literature was searched in the databases of Pubmed/Medline, Cochrane Clinical Trail Register and Embase from January 1980 to March 2011. Two investigators (AD and WZ) explored the databases independently. The articles with potentially applicable titles and/or abstracts were obtained and relevance was assessed. Potentially eligible articles were screened by two authors (AD and WZ) for applicability, and references of used publications were verified for additional studies meeting the inclusion criteria.

Data extracted from clinical studies included operative technique, functional outcome measures, complications and follow-up. From the biomechanical studies, the methods of testing and biomechanical outcome were assessed. Recommendations for clinical practice were graded from A to D (Tables 3, 4).

\section{Results}

Ninety-nine publications met the search criteria. After applying the exclusion criteria, 11 articles (five biomechanical and six clinical) were available for data extraction. Pooling of the data was not realistic due to heterogeneity of patient populations, the outcome measures and follow-up (Fig. 1).

\section{Biomechanical}

Five biomechanical studies were included involving 90 cadaveric ankles, ranging from a minimum of eight cadaveric ankles to a maximum of 26 ankles [10, 17, 22, $35,37]$. The first was published in 2005 and the most recent in 2011. The characteristics of these studies are shown in Table 1.

The ankles were tested in different ways: external/ internal rotation; dorsal/plantar flexion; eversion/inversion; pull out strength along the axis of the repair apparatus; and axial loading. Although most of the biomechanical studies report there is good resistance to axial and rotational loads, resistance to failure and with restoration of physiologic syndesmotic motion, Forsythe et al. [10] reported inadequate reduction in the syndesmosis at all forces applied. Soin et al. [35] showed similar fibular motions for the suture-button group and the syndesmotic screw group, with neither able to restore native ankle motion.

Forsythe et al. [10] studied external rotation force in two groups (4.5-mm cortical screws versus suture-button). Diastasis at different rotation forces was measured. The 
Table 1 Characteristics of mechanical studies

\begin{tabular}{|c|c|c|c|c|}
\hline Study & $n$ & Outcome & Method & Conclusion \\
\hline $\begin{array}{l}\text { Klitzman } \\
\text { et al. } \\
\text { [17] }\end{array}$ & $\begin{array}{l}8 \text { fresh } \\
\text { frozen } \\
\text { human } \\
\text { ankles }\end{array}$ & $\begin{array}{l}\text { Syndesmotic gap } \\
\text { Tibiofibular movement } \\
\text { Laxity due to cycling }\end{array}$ & $\begin{array}{l}\text { Cycling at submaximal loads in six- } \\
\text { degrees-of-freedom-machine } \\
\text { Dorsal/plantar flexion; internal/ } \\
\text { external rotation and inversion/ } \\
\text { eversion }\end{array}$ & $\begin{array}{l}\text { Good alternative for syndesmotic fixation. } \\
\text { More physiologic type of fixation and a good } \\
\text { ability to maintain reduction in syndesmosis. } \\
\text { No second surgery necessary }\end{array}$ \\
\hline $\begin{array}{l}\text { Soin et al. } \\
\text { [35] }\end{array}$ & $\begin{array}{l}\text { Ten pairs of } \\
\text { cadaveric } \\
\text { legs }\end{array}$ & $\begin{array}{l}\text { Fibular translations and } \\
\text { rotation }\end{array}$ & $\begin{array}{l}\text { Axial compression, external rotation } \\
\text { and combination } \\
\text { Linear variable displacement } \\
\text { transducer }\end{array}$ & $\begin{array}{l}\text { Screws were closer to native ankle motion in } \\
\text { AP and ML motions; } \\
\text { Suture-button was closer to native fibular } \\
\text { rotation }\end{array}$ \\
\hline $\begin{array}{l}\text { Forsythe } \\
\text { et al. } \\
{[10]}\end{array}$ & $\begin{array}{l}\text { Ten fresh } \\
\text { frozen } \\
\text { cadaveric } \\
\text { ankle pairs }\end{array}$ & $\begin{array}{l}\text { Maintain syndesmotic } \\
\text { reduction as compared to } \\
\text { metallic screw }\end{array}$ & $\begin{array}{l}\text { External rotation force on intact } \\
\text { ankles and after dissecting the } \\
\text { syndesmotic and deltoid ligaments }\end{array}$ & $\begin{array}{l}\text { The fibre wire button was unable to maintain } \\
\text { syndesmotic reduction in the ankle at any } \\
\text { forces applied }\end{array}$ \\
\hline $\begin{array}{l}\text { Thornes } \\
\text { et al. } \\
{[37]}\end{array}$ & $\begin{array}{l}\text { Sixteen } \\
\text { embalmed } \\
\text { cadaveric } \\
\text { legs }\end{array}$ & $\begin{array}{l}\text { Diastasis in suture-button } \\
\text { versus } 4 \text { cortical screw }\end{array}$ & $\begin{array}{l}\text { Generating an external rotation } \\
\text { torque }\end{array}$ & $\begin{array}{l}\text { Suture-endobutton fixation at least equals the } \\
\text { performance of screw fixation }\end{array}$ \\
\hline $\begin{array}{l}\text { Miller } \\
\text { et al. } \\
\text { [22] }\end{array}$ & $\begin{array}{l}26 \text { formalin- } \\
\text { preserved } \\
\text { cadaveric } \\
\text { legs }\end{array}$ & $\begin{array}{l}\text { Maximum load and } \\
\text { displacement at failure in } \\
\text { suture constructs and } \\
\text { tricortical screws }\end{array}$ & $\begin{array}{l}\text { Tested to failure along the axis of } \\
\text { the repair apparatus. Screw versus } \\
\text { suture at } 2 \text { and } 5 \mathrm{~cm} \text { above tibial } \\
\text { plafond }\end{array}$ & $\begin{array}{l}\text { Good alternative to internal fixation of ankle } \\
\text { mortise instability due to syndesmotic } \\
\text { rupture }\end{array}$ \\
\hline
\end{tabular}

Table 2 Characteristics of clinical studies

\begin{tabular}{|c|c|c|c|c|c|}
\hline Study & $n$ & Outcome & Method & Conclusion & $\begin{array}{l}\text { Level of } \\
\text { evidence }\end{array}$ \\
\hline $\begin{array}{l}\text { Cottom } \\
\text { et al. } \\
\text { [7] }\end{array}$ & $\begin{array}{l}50 \\
25 \text { Tightrope } \\
25 \text { screw }\end{array}$ & $\begin{array}{l}\text { AOFAS, } \\
\text { SF12 }\end{array}$ & $\begin{array}{l}\text { Single tightrope/double } \\
\text { tightrope versus screw } \\
\text { fixation }\end{array}$ & $\begin{array}{l}\text { AOFAS and SF12 no significant difference between screw } \\
\text { and tightrope, } 6 \text { months postoperatively }\end{array}$ & II \\
\hline $\begin{array}{l}\text { Thornes } \\
\text { et al. } \\
\text { [38] }\end{array}$ & $\begin{array}{l}3216 \text { screw } \\
16 \text { flexible } \\
\text { fixation }\end{array}$ & AOFAS & $\begin{array}{l}4 \text { cortices syndesmotic } \\
\text { screw fixation versus } \\
\text { suture-button fixation }\end{array}$ & $\begin{array}{l}\text { AOFAS was significantly better in the suture-button group } \\
\text { after } 3 \text { months and } 1 \text { year }\end{array}$ & III \\
\hline $\begin{array}{l}\text { Cottom } \\
\text { et al. } \\
{[6]}\end{array}$ & 25 & $\begin{array}{l}\text { AOFAS, SF } \\
12\end{array}$ & $\begin{array}{l}\text { Single tightrope/double } \\
\text { tightrope }\end{array}$ & $\begin{array}{l}\text { Method quick to perform. No complications, early weight- } \\
\text { bearing, early return to daily living, sports and work }\end{array}$ & IV \\
\hline $\begin{array}{l}\text { Willmott } \\
\text { et al. } \\
\text { [42] }\end{array}$ & 6 & $\begin{array}{l}\text { Radiological } \\
\text { evaluation }\end{array}$ & $\begin{array}{l}5 \text { single and one double } \\
\text { tightrope }\end{array}$ & $2 / 6$ removed. One because tender swelling over button & IV \\
\hline $\begin{array}{l}\text { Thornes } \\
\text { et al. } \\
\text { [38] }\end{array}$ & 12 & AOFAS & Single tightrope fixation & $\begin{array}{l}\text { No major complications, AOFAS mean } 87 \text { at FU at least } \\
6 \text { months, } 8 / 8 \text { returned to work in } 3-16 \text { week. Mean } \\
\text { dorsiflexion } 4.3 \text { beyond neutral versus } 8.7 \text { contralateral }\end{array}$ & IV \\
\hline $\begin{array}{l}\text { de Groot } \\
\text { et al. } \\
{[8]}\end{array}$ & 24 & AOFAS & $\begin{array}{l}\text { Single/double/triple } \\
\text { tightrope }\end{array}$ & $\begin{array}{l}\text { AOFAS } 94 \text { mean at last FU. ( } 20 \text { months) No major } \\
\text { complications. } 6 \text { devices removed. } 2 \times \text { suture-button with } \\
\text { subsidence } \\
\text { Despite this no worse functional outcome }\end{array}$ & IV \\
\hline
\end{tabular}

Table 3 Level of evidence

\begin{tabular}{ll}
\hline Level I & High-quality prospective randomized clinical trial \\
Level II & Prospective comparative study \\
Level III & Retrospective case control study \\
Level IV & Case series \\
Level V & Expert opinion \\
\hline
\end{tabular}

screw group retained syndesmotic reduction comparable to the intact specimen at both 2.5 and $5 \mathrm{Nm}$ of loading. The suture-button (fibre wire) group was unable to maintain reduction at the initial load of $2.5 \mathrm{Nm}$ as compared with intact specimens. Both groups were tested to a maximum load of $12.5 \mathrm{Nm}$ moment; beyond this load many of the ankles failed. 
Table 4 Grades of recommendation (given to various treatment options based on the level of evidence supporting that treatment)

Grade A

Grade B

Grade C

Grade D
Treatment options are supported by strong evidence (consistent with level I or II studies) Treatment options are supported by fair evidence (consistent with level III or IV studies) Treatment options are supported by either conflicting or poor quality evidence (level IV studies) When insufficient evidence exists to make a recommendation
Fig. 1 Flowchart summarizing the selection of relevant articles

Inclusion criteria:
$>18$ years
Syndesmotic injury
Flexible fixation
English, German, Dutch literature

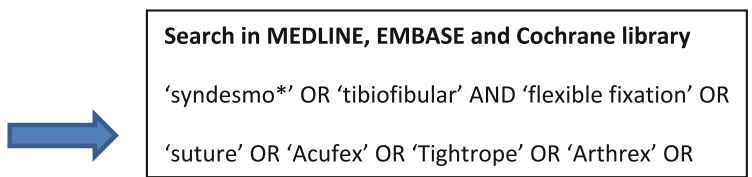

Screening related articles and

references.

(2)
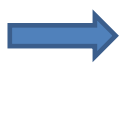

Excluded articles:
Animal studies
Less than 2 patients
Chronic syndesmotic injuries
Other fixation techniques used

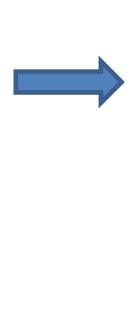

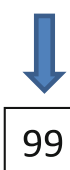

99
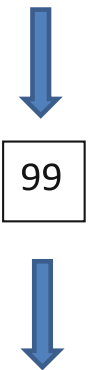

11

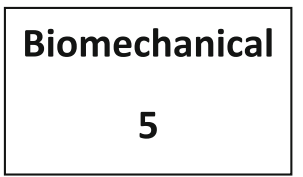

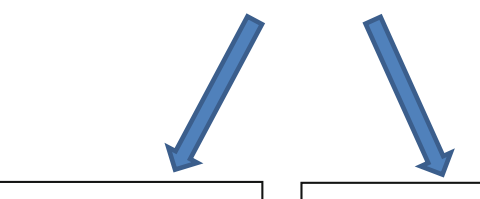

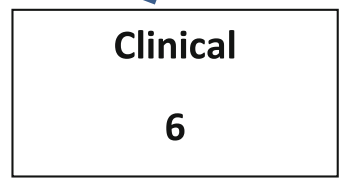

Thornes et al. [37] and Klitzman et al. [17] did not have any failures in constructs in either group. Klitzman et al. [17] found that the syndesmotic gap after cycling was not significantly different between the intact group and suturebutton group. The screw fixation group had a significantly smaller gap as compared to the two other groups. With increasing external rotation torque, up to $8 \mathrm{~kg}(20 \mathrm{Nm})$, Thornes et al. [37] found that the mean diastasis increased gradually in both groups, and these differences were not statistically significant. The suture-button group did give a more consistent performance, a more gradual increase in diastasis compared to the screw fixation.

In the cadaver study by Soin et al. [35], both the suturebutton and the screw fixation samples were tested until failure. The screw fixation group had a significantly higher failure torque (median $26.5 \mathrm{Nm}, p=0.02$ ) than did the suture-button group (median 23.6 Nm). None of the failures in the suture-button group were due to hardware failure; the screw became bent in three cases of the screw group, but the higher failure torque in the screw group has to be taken into account.

Miller et al. [22] tested the pull out strength 2.0 and $5.0 \mathrm{~cm}$ above the tibial plafond. There was no significant difference in strength or displacement between the suturebutton and the tricortical screw at either 2.0 or $5.0 \mathrm{~cm}$. The fixation at $5.0 \mathrm{~cm}$ had significantly increased holding strength over fixation at $2.0 \mathrm{~cm}$, and the fixation had a significant greater displacement at $2.0 \mathrm{~cm}$ than at $5.0 \mathrm{~cm}$. 


\section{Clinical}

The clinical studies involved 149 ankles in six studies, with four of these studies being case series [6-8, 36, 38, 42]. The studies demonstrated high functional results with the AOFAS score; there was faster rehabilitation with the suture-button than with screw fixation. Table 2 shows the characteristics and general conclusions of these studies. No major complications were reported in these series, and all authors described the technique as easy and quick to perform. Complications seen in the suture-button group mostly involved hardware removal due to local irritation of the overlying soft tissue $[8,42]$. Twelve and sixteen screws had to be removed in the studies by Thornes et al. [38] and Cottom et al. [7], respectively, as compared to none of the suture-buttons. In the study by Thornes et al. [38], no welldefined reasons for screw removal were given, whereas in the study by Cottom et al. [7], the major reasons for removal were screw loosening and screw breakage.

\section{Discussion}

We initiated this work to review the literature on restoration of syndesmotic stability by a suture-button device and to formulate recommendations for clinical practice and future research. The questions were as follows: Is the suture-button fixation secure? Is it efficient? Is it costeffective?

The distal tibiofibular syndesmosis is not a static structure. When loaded, in gait or passive movement, the syndesmosis allows for three-dimensional motion [1, 3, 26, 31]. Suture-button stabilization of the syndesmosis is thought advantageous as physiologic ankle motions are possibly better preserved, and this potential benefit may lead to better functional outcome. In the article by Thornes et al. [38], patients with suture-button fixation showed better scores in AOFAS scale compared to the screw fixation group and had returned to work earlier. Conversely, Cottom et al. [8] compared both groups and did not find any significant differences in time to postoperative weightbearing or subjective outcome scores between both groups.

The syndesmotic screw is removed 8-10 weeks after placement usually. This is a second operation with additional cost, new functional limitations and a risk of infection $[15,27,28,30,34]$. This contrasts with discussion over the removal of screws; since the publication of a study by Hamid et al. [13], it was shown that a broken screw gives better AOFAS scores than those who had screws removed. Added to this debate, hardware complaints and subsequent need for the removal of the suture-button have been reported [8, 42]. As such, it is not yet clear how this potential benefit should be valued.
This review of the literature suggests some good potential for use of the suture-button in syndesmotic instability. Although the studies are heterogeneous, both clinical (from level II to level IV) and biomechanical (different sources of cadaveric models, different testing), most articles show encouraging results with greater physiologic motion, a good functional outcome and few complications.

\section{Security and effectiveness}

Forsythe et al. [10] were the only investigators who reported a poor outcome from the suture-button in biomechanical testing. They concluded that there was poor ability of the suture to maintain syndesmotic reduction. The authors acknowledged that the ankles may have been tested in supra-physiologic conditions (external rotation torque up to $12.5 \mathrm{Nm}$ ). This is confirmed by Shoemaker et al. [33] who described 7.5 $\mathrm{Nm}$ to be the external rotation torque that was $75 \%$ of the value reported to elicit discomfort in vivo. Nevertheless, with even lower values of external rotation torque, they found a significant better outcome in the syndesmotic screw group. We agree the authors have tested the ability to retain syndesmotic reduction during external rotation but used forces of a magnitude that was not physiologic. Therefore, the relevance of testing stability of the syndesmotic reduction during external rotation and with forces of such magnitude is questionable.

The other biomechanical studies showed a good ability of the suture-button implant to retain syndesmotic reduction. They revealed also another advantage of this type of fixation which was the preservation of physiologic tibiofibular movement [16, 37]. In contrast, Tornetta et al. [39] showed in their biomechanical study that this does not lead to reduced range of motion, whereas Klitzman et al. [17] described a smaller syndesmotic gap after screw fixation.

From clinical studies, Cottom et al. [7] found no significant difference in clinical outcome at 8-11-month follow-up but a slight but significant difference was found in the tibiofibular clear space from radiological evaluation. The clinical relevance of this observation is not clear, and as stated by Beumer et al. [3], quantitative measurement of syndesmotic parameters in repeated ankle radiographs may be of little value. The limited follow-up in this study prevents any conclusive statements over the long-term results.

In a level III retrospective cohort study by Thornes et al., the AOFAS scores after 3 months and 1 year were significantly higher in the suture-button group than in patients with a conventional screw. They reported a faster return to work. Although the higher AOFAS scores at 3 months may have been influenced by the earlier weightbearing ability in the 'flexible' fixation group, this 
difference, which remained at the 1 year follow-up, was unlikely to have been influenced by weight-bearing at that late stage [38]. None of the patients treated with suturebutton fixation required removal compared with $75 \%$ of patients treated with screw fixation.

All case series (clinical and biomechanical) comment on the speed and ease of the suture-button fixation technique, making it no more complicated than standard screw stabilization. Although no major complications were seen in any of the clinical studies, two authors reported on the need of suture-button removal from local irritation.

Little is known about the long-term outcome of the suture-button fixation since it is a fairly new procedure and the longest available follow-up is only 20 months. Longterm results are needed to confirm the early promising results for the future.

\section{Cost-effectiveness}

One of the advantages attributed to the suture-button technique is the absence of the need for a second operation to remove hardware. Suture-button stabilization seems to be more expensive due to costs of the implant (343 euro for Tightrope Arthrex, 38 euro for conventional Synthes stainless screw, $50 \mathrm{~mm}$ ). As there is no need for second surgery, which is practised in most hospitals after syndesmotic fixation with a screw, the cost difference will be less. This advantage becomes less important as some authors advocate suture-button removal and others, who practice screw fixation, advocate leaving the screw in situ $[8,13,42]$.

The clinical case series report a good functional outcome and early return to work for the suture-button groups, but the design of the included studies prevents conclusive statements to be made based on the available data.

\section{Conclusion}

Recommendations for clinical practice

The reported advantages of suture-button fixation as compared with traditional stabilization with a screw in repairing a syndesmotic injury include the ability for immediate postoperative weight-bearing, a more physiologic movement at the tibiofibular joint and avoidance of a second operation for hardware removal. The current literature conveys agreement that the technique for placement of a suture-button is easy and quick and the early weight-bearing allowed facilitates a quicker return to work. Whilst the costs are substantially higher, the shortterm clinical results are good but there are no long-term results known.
Open Access This article is distributed under the terms of the Creative Commons Attribution License which permits any use, distribution, and reproduction in any medium, provided the original author(s) and the source are credited.

\section{References}

1. Ahl T, Dalen N, Lundberg A et al (1987) Mobility of the ankle mortise. A roentgen stereophotogrammetric analysis. Acta Orthop Scand 58(4):401-402

2. Bartonicek J (2003) Anatomy of the tibio-fibular syndesmosis and its clinical relevance. Surg Radiol Anat 25(5-6):379-386

3. Beumer A, Valstar ER, Garling EH et al (2003) Kinematics of the distal tibio-fibularsyndesmosis: radiostereometry in 11 normal ankles. Acta Orthop Scand 74(3):337-343

4. Bostman OM, Pihlajamaki HK (2000) Adverse tissue reactions to bioabsorbable fixation devices. Clin Orthop 371:216-227

5. Brown OL, Dirschl DR, Obremskey WT (2001) Incidence of hardware-related pain and its effect on functional outcomes after open reduction and internal fixation of ankle fractures. J Orthop Trauma 15(4):271-274

6. Cottom JM, Hyer CF, Philbin TM et al (2008) Treatment of syndesmotic disruptions with the Arthrex Tightrope: a report of 25 cases. Foot Ankle Int 29(8):773-780

7. Cottom JM, Hyer CF, Philbin TM et al (2009) Transosseous fixation of the distal tibio-fibular syndesmosis: comparison of an interosseous suture and endobutton to traditional screw fixation in 50 cases. J Foot Ankle Surg 48(6):620-630

8. De Groot H, Al-Omari AA, El Ghazaly SA (2011) Outcomes of suture button repair of the distal tibio-fibular syndesmosis. Foot Ankle Int 32(3):250-256

9. De Souza LJ, Gustillo RB, Meijer TJ (1985) Results of operative treatment of displaced external rotation-abduction fractures of the ankle. JBJS Am 67(7):1066-1074

10. Forsythe K, Freedman KB, Stover MD et al (2008) Comparison of a novel fiberwire-button construct versus metallic screw fixation in a syndesmotic injury model. Foot Ankle Int 29(1):49-54

11. Fritschy D (1989) An unusual ankle injury in top skiers. Am J Sports Med 17:282-285

12. Hahn DM, Colton CL (2000) Fractures of the malleoli. In: Ruedi TP, Murphy WM, Colton CL et al. (eds) AO principles of fracture management. AO publishing, Davos, p 581

13. Hamid N, Loeffler BJ, Braddy W, Kellam JF, Cohen BE, Bosse MJ (2009) Outcome after fixation of ankle fractures with an injury to the syndesmosis: the effect of the syndesmosis screw. J Bone Joint Surg Br 91(8):1069-1073

14. Hansen L (1950) N: fractures of the ankle. II. Combined experimental-surgical and experimental-roentgenologic investigations. Arch Surg 60:957-985

15. Kennedy JG, Soffe KE, DallaVedova P et al (2000) Evaluation of the syndesmotic screw in low Weber $\mathrm{C}$ ankle fractures. J Orthop Trauma 14(5):359-366

16. Kerkhoffs GM, Rowe BH, Kelly K et al. (2002) Immobilisation and functional treatment for acute lateral ankle ligament injuries in adults. Cochrane Database Syst Rev 3(3):CD003762

17. Klitzman R, Zhao H, Zhang LQ et al (2010) Suture-button versus screw fixation of the syndesmosis: a biomechanical analysis. Foot Ankle Int 31(1):69-75

18. Lundberg A (1989) Kinematics of the ankle and foot- in vivo roentgen stereophotogrammetry. Acta Orthop Scand Suppl 223:1-24

19. Marqueen T, Owen J, Nicandri G et al (2006) Comparison of the syndesmosis staple to the transsyndesmotic screw; a biomechanical study. Foot Ankle Int 26:224-230 
20. Michelson J, Solocoff D, Waldmann B et al (1997) Ankle fractures; the Lauge-Hansen classification revised. Clin Orthop 345:198-205

21. Miller CD, Shelton WR, Barret GR et al (1995) Deltoid and syndesmosis ligament injury of the ankle without fracture. Am J Sports Med 23:746-750

22. Miller RS, Weinhold PS, Dahners LE (1999) Comparison of tricortical screw fixation versus a modified suture construct for fixation of ankle syndesmosis injury: a biomechanical study. J Orthop Trauma 13(1):39-42

23. Muller ME, Brandi W (1970) Manuel of internal fixation; techniques recommended by the AO group. Springer, New York

24. Ogilvie-Harris DJ, Reed SC, Hedman TP (1994) Disruption of the ankle syndesmosis: biomechanical study of the ligamentous restraints. Arthroscopy 10(5):558-560

25. Pankovich AM (1976) Maisonneuve fractures of the fibula. JBJS Am 58:337-342

26. Peter RE, Harrington RM, Henley MB et al (2004) Biomechanical effects of internal fixation of the distal tibio-fibular syndesmotic joint: comparison of two fixation techniques. J Orthop Trauma 8(3):215-219

27. Raahave D (1976) Postoperative wound infection after implant and removal of osteosynthetic material. Acta Orthop Scand 47(1):28-35

28. Richards RH, Palmer JD, Clarke NM (1992) Observations on removal of metal implants. Injury 23(1):25-28

29. Roberts RS (1983) Surgical treatment of displaced ankle fractures. Clin Orthop 172:164-170

30. Sanderson PL, Ryan W, Turner PG (1992) Complications of metalwork removal. Injury 23(1):29-30

31. Scranton Jr PE, McMaster JG, Kelly E (1976) Dynamic fibular function: a new concept. Clin Orthop Relat Res 118:76-81
32. Scraton Jr PE, McMaster JG, Kelly E (1976) Dynamic fibular function; a new concept. Clin Orthop 118:76-81

33. Shoemaker SC, K1 M (1982) In vivo rotary knee stability. Ligamentous and muscular conditions. JBJS Am 64(2):208-216

34. Sinisaari I, Patiala H, Bostman O et al (1996) Metallic or absorbable implants for ankle fractures: a comparative study of infections in 3,111 cases. Acta Orthop Scand 67(1):16-18

35. Soin SP, Knight TA, Dinah AF et al (2009) Suture-button versus screw fixation in a syndesmosis rupture model: a biomechanical comparison. Foot Ankle Int 30(4):346-352

36. Thornes B, McCartan D (2006) Ankle syndesmosis injuries treated with the Tightrope Suture-Button Kit. Tech Foot Ankle Surg. 5:45-53

37. Thornes B, Walsh A, Hislop M et al (2003) Suture-endobutton fixation of ankle tibio-fibular diastasis: a cadaver study. Foot Ankle Int 24(2):142-146

38. Thornes B, Shannon F, Guiney AM et al (2005) Suture-button syndesmosis fixation: accelerated rehabilitation and improved outcomes. Clin Orthop Relat Res 431:207-212

39. Tornetta P 3rd, Spoo JE, Reynolds FA et al (2001) Overtightening of the ankle syndesmosis; is it really possible? JBJS Am 83-A(4):489-492

40. Van den Bekerom MPJ, Raven EEJ (2007) Current concepts review: operative techniques for stabilizing the distal tibio-fibular syndesmosis. Foot Ankle Int 28:1302-1308

41. Veltri DM, Pagnani MJ, O'Brien SJ et al (1995) Symptomatic ossification of the tibio-fibularsyndesmosis in professional football players; a sequela of the syndesmotic ankle sprain. Foot Ankle Int 16:285-290

42. Willmott HJ, Singh B, David LA (2009) Outcome and complications of treatment of ankle diastasis with tightrope fixation. Injury 40(11):1204-1206 